\title{
The protective effect of Ganoderma lucidum on testicular torsion/detorsion-induced ischemia-reperfusion (I/R) injury ${ }^{1}$
}

\author{
Gül Doğan' (D) , Hülya İpek" (iD
}

' MD, Hitit University Faculty of Medicine, Department of Pediatric Surgery, Çorum, Turkey. Acquisition of data, manuscript writing.

" MD, Hitit University Erol Olcok Training and Research Hospital, Department of Pediatric Surgery, Çorum, Turkey. Acquisition of data, manuscript preparation.

\begin{abstract}
Purpose: To investigate the protective effect of Ganoderma lucidum on testicular torsion/detorsion $(T / D)$-induced ischemia-reperfusion (I/R) injury.

Methods: Thirty male Wistar albino rats were randomly categorized into 3 groups: Group 1: sham, Group 2 ( T/D): 2,5 hours of ischemia and 7 days of reperfusion, Group 3 (T/D+G. lucidum): 2,5 hours of ischemia and 7 days of reperfusion and 7 days of $20 \mathrm{mg} / \mathrm{kg}$ via gastric gavage G. lucidum polysaccharides per day. Biochemical assays of Malondialdehyde (MDA), superoxide dismutase (SOD), Catalase (CAT), Glutathione (GSH) levels, histopathology and expression levels of VEGF and Bcl-2 with immunohistochemical methods were examined in testicular tissue.
\end{abstract}

Results: G. lucidum treatment was found to have prevented the T/D-induced I/R injury by decreasing MDA levels of the testis. SOD, CAT and GSH activities were decreased in group 2, while they were increased in group $3(p<0.001)$ and significant improvement in the tube diameter was observed in group 3. Bcl-2-positive germinal cells were lowered in group 3 compared to the group 2. VEGF expression showed an increase in group 2, whereas it decreased in group 3.

Conclusion: The antioxidant $G$. lucidum is thought to induce angiogenesis by reducing the apoptotic effect in testicular torsion-detorsion.

Key words: Spermatic Cord Torsion. Testis. Reishi. Vascular Endothelial Growth Factor A. Lymphoma, B-Cell. Rats. 


\section{- Introduction}

Testicular torsion is among the most common urological emergencies observed in children. The annual incidence of spermatic cord torsion is 4.5 in 100,000 males aged $1-25$ years $^{1}$. This condition may cause ischemia and loss of the testis. Testicular damage varies depending on the grade and duration of the torsion ${ }^{2}$. Testicular torsion decreases blood flow to the testis, causing tissue ischemia. The accumulation of reactive oxygen species (ROS) is the underlying pathologic mechanism of testicular torsion followed by ischemia, and it has been observed to lead to infertility in several cases $^{3}$. ROS is known to react with proteins, lipids, carbohydrates and nucleic acids, causing impaired cell function, DNA damage and apoptosis. The extent of testicular tissue damage is related to both the degree of twisting and the rapidity of surgical intervention to counter-rotate both the testis and spermatic cord to re-establish normal blood flow to the organ ${ }^{4}$. Previous studies using a rat model of testicular torsion have demonstrated that a 1 -hour, $720^{\circ}$ rotation of the testes followed by reperfusion results in permanent loss of spermatogenesis despite the return of blood flow. If treated within 6 hours of presenting with pain, there is a good chance of saving the affected testicle, as $90 \%$ $100 \%$ testicles will be saved. If treated within 6-12 h, $20 \%-50 \%$ testicles will be saved depending on the degree of the torsion, and if treated within 12-24 h, $0 \%-10 \%$ testicles will be saved ${ }^{5}$. Delayed surgery may result in orchiectomy or diminished fertility, and even if the testis is detorsed in time, infertility risk is the most worrisome complication ${ }^{6}$.

Ganoderma lucidum (G. lucidum) is a mushroom belonging to the Polyporaceae family of Basidiomycota and has been widely used as a traditional medicine for thousands of years, particularly in Asian countries ${ }^{7}$. The fruiting bodies, cultured mycelia and spores of $G$. lucidum contain a variety of bioactive chemical substances such as polysaccharides, triterpenoids and proteins ${ }^{8}$. Different experimental studies and modern clinical trials suggest that these active compounds isolated from $G$. lucidum have anti-inflammatory, antioxidant, antitumor and immunomodulatory activities ${ }^{9}$.

Though several compounds have been used to heal ischemia-reperfusion ( $/ / R)$ injury in animal models of testicular torsion, few are available for use $\mathrm{e}^{10}$. However, to date, there is no study on the effect of G. lucidum on a rat testicular torsion model. In our study, biochemical assays of malondialdehyde (MDA), superoxide dismutase (SOD), catalase (CAT), glutathione (GSH) levels, histopathology and expression levels of vascular endothelial growth factor (VEGF) and B-cell lymphoma 2 (Bcl-2) were examined in testicular tissue by immunohistochemical methods.

Thus, the aim of the present study was to determine whether treatment with G.lucidum with antioxidant properties ameliorated testicular damage caused by torsion/detorsion (T/D) injury using histopathological, biochemical and immunohistochemical methods.

\section{- Methods}

All experimental protocols conducted on animals were consistent with the National Institutes of Health Guidelines for the Care and Use of Laboratory Animals and were approved by the Health Sciences University, Ankara Education and Research Hospital Ethics Committee of Animal Care and Usage. Thirty male Wistar albino rats with a mean weight of 200-250 gr were used. They were housed in an air-conditioned room with 12-h light and dark cycles, where the temperature $\left(23 \pm 2^{\circ} \mathrm{C}\right)$ and relative humidity $(65-70 \%)$ were kept constant.

In this study, all surgical procedures were performed by the intramuscular injection of ketamine hydroxide (Ketalar', Pfizer, Turkey) (50 mg/kg) and xylazine (Rompun", Bayer, Germany) (10 mg/kg) for general anesthesia. All operations were performed under sterile conditions. Animals were randomly divided into three groups. Ten adult male rats were used in each group. Group 1 was assigned as the sham group. No treatment was applied to this group, and only the left testis was taken, and the rats were sacrificed under anesthesia. In Group 2 (T/D group), torsion was created by rotating the left testis $720^{\circ}$ degrees clockwise along the longitudinal axis of spermatic cord for 2.5 hours under anesthesia. At the end of the 2.5 hours, the testis was corrected to its original position and left for 7 days for the detorsion procedure. In Group 3 (T/D+G. lucidum), after T/D, the rats were given $G$. lucidum polysaccharides (GLPS) (20 $\mathrm{ml} / \mathrm{kg}$ ) via gastric gavage for 7 days. Group 2 received similar volumes of the same fluid that did not contain G. lucidum polysaccharides. After 7 days of reperfusion, re-explorations and orchiectomies were performed on each rat in groups 2 and 3 .

Testicular samples were fixed in neutral buffered formalin solution, directly dehydrated in ascending series of ethanol solution and embedded in paraffin wax. Five-micrometer sections were cut with a microtome (RM2265 rotary microtome; Leica, Germany) and mounted on coated slides. The sections were stained with Periodic Acid Schiff (PAS) and analyzed under a light microscope (Zeiss, Germany).

In this study, primary outcome measure consisted of the changes of MDA, SOD, CAT and 
GSH levels of biochemical parameters. Secondary outcome measure consisted of histopathologic and immunohistochemical changes.

\section{Surgical procedure}

The rats were anesthetized by an intramuscular injection of ketamine hydroxide $(50 \mathrm{mg} / \mathrm{kg})$ and xylazine $(10 \mathrm{mg} / \mathrm{kg})$ under aseptic conditions. The tunica vaginal was removed with the help of a forceps to allow the testicular tissue to be visible. A scrotal pocket was created to place the testicle back into the scrotum after torsion. To create torsion, the left testis was rotated at $720^{\circ}$ degrees clockwise around the longitudinal axis of spermatic cord for 2.5 hours. To prevent detorsion, the testis was fixed into the scrotal pocket by passing 4/0 non-traumatic absorbable suture through the dartos and testicular tunica albuginea. After 2.5 hours of torsion, the suture that fixed testis to dartos was cut for detorsion and the reperfusion period of the following 7 days.

\section{Biochemical analysis}

MDA, SOD, CAT and GSH levels were examined in testicular tissue. Tissue samples were homogenized with ice-cold 150 mMKC. MDA levels were assayed for products of lipid peroxidation, and the results were expressed as nmol MDA/g tissue ${ }^{11}$. The SOD activity in the tissue was measured using the RANSOD kit (Randox Laboratories, Crumlin, UK). GSH was determined by the spectrophotometric method based on the use of Ellman's reagent, and the results were expressed as $\mu$ mol glutathione/g tissue ${ }^{12}$. CAT activity was determined by the spectrophotometric method based on the ability of hydrogen peroxide to form a stable stained complex with molybdenum salts ${ }^{13}$.

\section{Immunohistochemical technique}

Formaldehyde-fixed testis tissue was embedded in paraffin wax for further immunohistochemical examination. Sections were deparaffinized in xylene. The antigen retrieval process was performed twice in citrate buffer solution ( $\mathrm{pH} 6.0$ ), first for 7 minutes, and then for 5 minutes, and was boiled in a microwave oven at 700 $W$. They were then allowed to cool to room temperature for 30 minutes and washed twice in distilled water for 5 minutes. Endogenous peroxidase activity was blocked in $0.1 \%$ hydrogen peroxide for 20 minutes. Ultra $\mathrm{V}$ block (Cat. No. 85-9043, Invitrogen, Carlsbad, California, USA) was applied for 10 minutes prior to the application of primary antibodies for $\mathrm{Bcl}-2$ (cat: PA5-20068, Invitrogen, Carlsbad, California, USA) and VEGF (cat: PA5-16754,
Invitrogen, Carlsbad, California, USA). Secondary antibody (Cat. No. 85-9043, Invitrogen, Carlsbad, California, USA) was applied for 20 minutes. Slides were then exposed to streptavidin-peroxidase for 20 minutes. Chromogen diaminobenzidine (DAB, Cat. No. 34002, Invitrogen, Carlsbad, California, USA) was used. Control slides were prepared as mentioned above, but by omitting the primary antibodies. After counter staining with hematoxylin and washing in tap water for 8 minutes and in distilled water for 10 minutes, sections were examined using a light microscope (Zeiss, Germany).

\section{Statistical analysis}

Statistical analyses were conducted using SPSS (Version 22.0, SPSS Inc., Chicago, IL, USA). Descriptive statistics are presented as median (min-max) and mean \pm standard deviation (SD). The normal distribution of the data was evaluated by Shapiro-Wilks test. Since data normality distribution was met, the groups were compared by an analysis of variance (ANOVA) followed by Tukey's multiple comparison tests to determine which groups differed with pairwise comparison. The priori sample size and post-hoc power analyses were calculated using the G-power (Version 3.1) package. The sample size was calculated for ANOVA test, which was used to test the main hypothesis of the study. As a result of the sample size analysis performed using previous study knowledge, it was found that 30 rats, 10 in three different groups, needed to be involved in the study to reveal the significant differences in the groups using $80 \%$ power $(1-\beta=0.80), \alpha=0.05$ error ( $95 \%$ confidence interval) with a two-sided hypothesis. Values of $\mathrm{p}<0.05$ were considered statistically significant.

\section{- Results}

\section{Biochemical results}

MDA levels in the testicular tissues of rats in the $T / D$ group were significantly increased compared to the sham group, while the MDA levels in the $T / D+G$. lucidum group were significantly decreased compared to the T/D group. G. lucidum treatment prevented the T/D-induced augmentation of MDA levels in the testis. The SOD, CAT and GSH activities of testicular tissue significantly decreased in the T/D group compared to the sham group. These values were significantly increased in the $T / D+G$. lucidum group compared to the $T / D$ group. The MDA, SOD, CAT and GSH levels of the sham, T/D and T/D + G. lucidum groups are shown in Table 1 (Fig. 1). 
Table 1 - Comparison of MDA, SOD, CAT and GSH activities in groups 1, 2 and 3.

\begin{tabular}{|c|c|c|c|c|c|}
\hline & Groups & $\mathbf{N}$ & Mean \pm SD & $P$ value & Post-hoc P value \\
\hline \multirow{3}{*}{ MDA } & 1 & 10 & $6.47 \pm 0.44$ & \multirow{3}{*}{$<0.001 *$} & $1-2:<0.001 *$ \\
\hline & 2 & 10 & $13.08 \pm 0.52$ & & 1-3: 0.965 \\
\hline & 3 & 10 & $6.52 \pm 0.29$ & & $2-3:<0.001 *$ \\
\hline \multirow{3}{*}{ SOD } & 1 & 10 & $3.52 \pm 0.62$ & \multirow{3}{*}{$<0.001 *$} & $1-2:<0.001 *$ \\
\hline & 2 & 10 & $1.66 \pm 0.14$ & & 1-3: 0.861 \\
\hline & 3 & 10 & $3.60 \pm 0.07$ & & $2-3:<0.001 *$ \\
\hline \multirow{3}{*}{ CAT } & 1 & 10 & $0.045 \pm 0.004$ & \multirow{3}{*}{$<0.001 *$} & $1-2:<0.001 *$ \\
\hline & 2 & 10 & $0.016 \pm 0.002$ & & $1-3: 0.182$ \\
\hline & 3 & 10 & $0.042 \pm 0.004$ & & $2-3:<0.001 *$ \\
\hline \multirow{3}{*}{ GSH } & 1 & 10 & $363.1 \pm 12.5$ & \multirow{3}{*}{$<0.001 *$} & $1-2:<0.001 *$ \\
\hline & 2 & 10 & $311.7 \pm 5.6$ & & $1-3: 0.822$ \\
\hline & 3 & 10 & $365.5 \pm 7.9$ & & $2-3:<0.001 *$ \\
\hline
\end{tabular}

Statistically significant: $p<0.05^{*}$

Groups; 1: Sham 2: Torsion-Detorsion 3: Torsion-Detorsion+G. lucidum

MDA: malondialdehyde SOD: superoxide dismutase CAT: catalase GSH: glutathione SD: Standard deviation

Power of MDA: $100 \%$, Power of SOD: $81 \%$, Power of CAT: $100 \%$, Power of GSH: $99 \%$
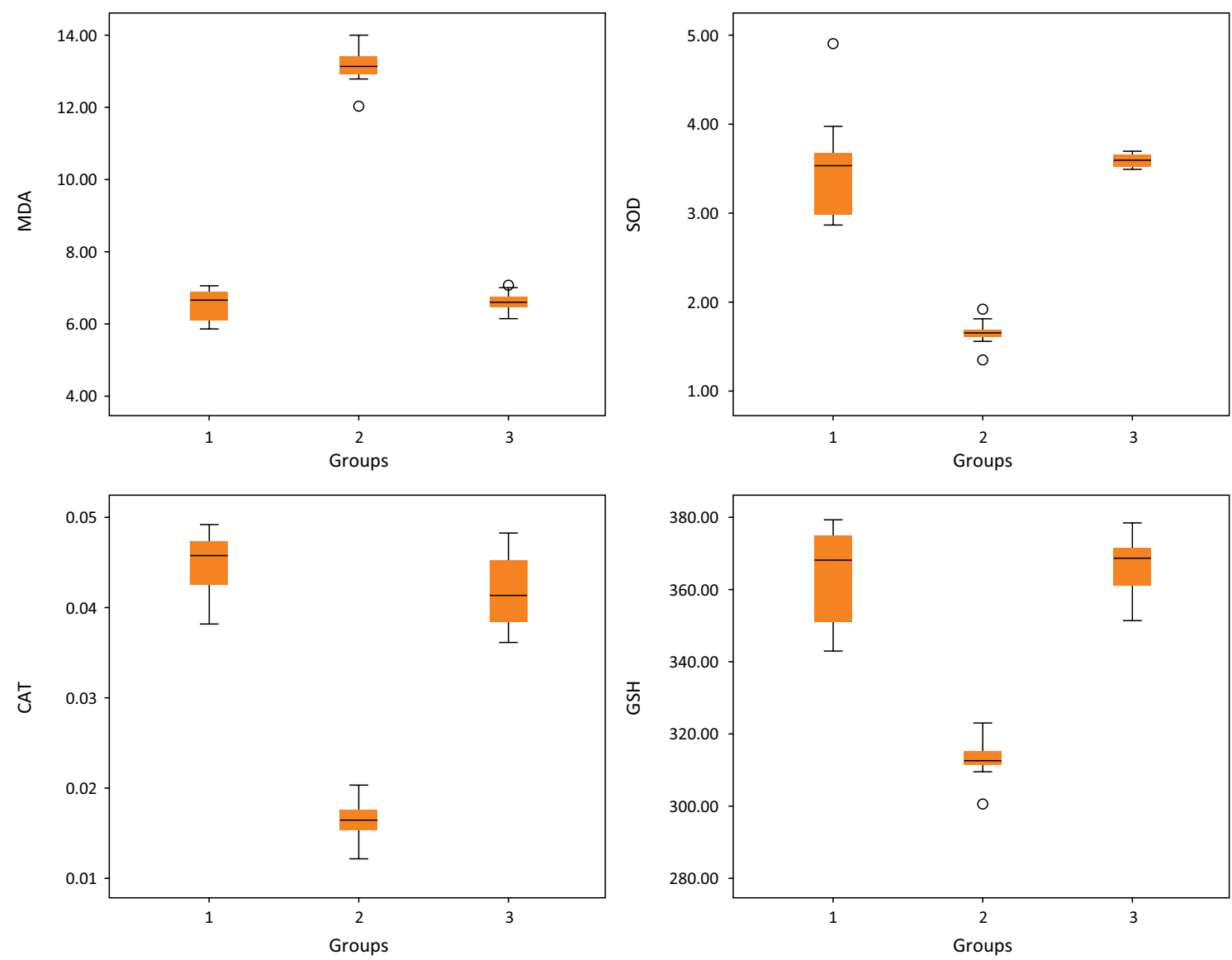

Groups; 1: Control; 2: Torsion-Detorsion; 3: Torsion-Detorsion+G. lucidum MDA: malondialdehyde SOD: superoxide dismutase CAT: catalase GSH: glutathione

Figure 1 - Comparison of MDA, SOD, CAT and GSH activities in control, T/D and T/D +G. lucidum groups on the boxplot graph. 


\section{Histopathologic results}

Testicular tubule diameter measurements were evaluated among the groups. There was a significant difference between the sham, T/D and T/D+G.lucidum groups $(p<0.001)$. According to the tube diameter measurement results, a significant improvement in the tube diameter was observed in the group treated with G.lucidum after T/D injury (Table 2, Fig. 2).

Table 2 - Diameter of seminiferous tubules.

\begin{tabular}{lccccc} 
& Groups & N & Mean \pm SD & P value & $\begin{array}{c}\text { Post-hoc } \\
\text { P value }\end{array}$ \\
\hline & 1 & 10 & $308.9 \pm 6.22$ & & $\begin{array}{c}\mathbf{1 - 2 :} \\
<\mathbf{0 . 0 0 1 *}\end{array}$ \\
$\begin{array}{l}\text { Diameterof } \\
\begin{array}{l}\text { Semiferous } \\
\text { tubules }\end{array}\end{array}$ & 2 & 10 & $265.3 \pm 12.27$ & $<\mathbf{0 . 0 0 1 *}$ & $\begin{array}{c}1-3: \\
0.930 \\
\end{array}$ \\
& 3 & 10 & $307.33 \pm 9.04$ & $\begin{array}{l}\mathbf{2 - 3 :} \\
<\mathbf{0 . 0 0 1 *}\end{array}$ \\
\hline
\end{tabular}

Groups; 1: Sham 2: Torsion-Detorsion 3: Torsion-Detorsion+G. lucidum

Power $100 \%$

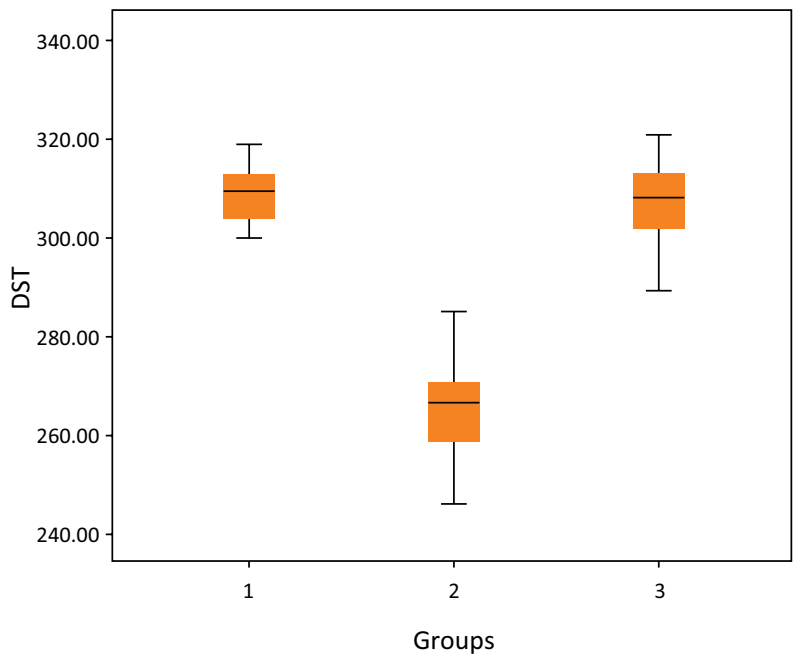

Groups; 1:Control 2:Torsion-Detorsion 3:Torsion-Detorsion+G. lucidum

Figure $\mathbf{2}$ - The boxplot graph of Diameter of Seminiferous Tubules (DST).

Testicular tissue was histologically examined under light microscope for all groups. In the sham group, seminiferous tubules had normal structure. Spermatic cells in seminiferous tubules were regular oval and mitotically active towards the lumen. The large luminal faces of Sertoli cells were regularly seen. The membrane thickness was normal. The intertubular space, connective tissue cells, blood vessels and Leydig cells were normal (Fig. 3A). In the T/D group, basal membrane thickness of tubules increased. Pyknosis and deteriorated nuclei of the spermatogenic cells, attenuated maturation in the sperm cells and degenerated Sertoli cells were observed. Hemorrhage and dilatation in the blood vessels of the interstitial area, increased connective tissue and degenerated Leydig cells were prominent (Fig. 3B). The $T / D+G$. lucidum group showed a decrease in the basal membrane thickness of tubules compared to the T/D group. Degenerated and deteriorated spermatic cells were evident in some tubules, along with mitotic increase. Little hemorrhage was observed in the blood vessels of the interstitial regular connective tissue cells and heterochromatin Leydig cells (Fig. 3C).

\section{Immunohistochemical results}

In the sham group, negative VEGF expression was observed in germ and Sertoli cells, vascular interstitial endothelial cells and Leydig cells (Fig. 3D). In the T/D group, the expression of VEGF in the apical faces of spermatogenic cells and Sertoli cells was positive. VEGF expression was positive in endothelial, some inflammatory, Leydig cells and interstitial blood vessels (Fig.3E). In the $T / D+G$. lucidum group, positive VEGF expression was observed in a small number of spermatogenic cells, particularly Sertoli cells. However, it was negative in interstitial endothelial cells and Leydig cells (Fig. 3F).

$\mathrm{Bcl}-2$ expression was negative in spermatogenic cells and Sertoli cells in the sham group, while it was positive in several small spermatid cells near the lumen (Fig. 3G). In the T/D group, intense Bcl-2 expression was observed in spermatogenic cells with strong mitotic activity in the basal layers of tubules. Significant expression of $\mathrm{Bcl}-2$ was observed in the luminal faces of some Sertoli cells (Fig. $3 \mathrm{H}$ ). In the basal and apical regions of the tubules, $\mathrm{BCl}-2$ reaction was positive in a few spermatogenic cells, whereas it was negative in Sertoli and Leydig cells. Bcl-2-positive germinal cells were also fewer in the G. lucidumtreated group compared to the T/D group (Fig. 3I). 

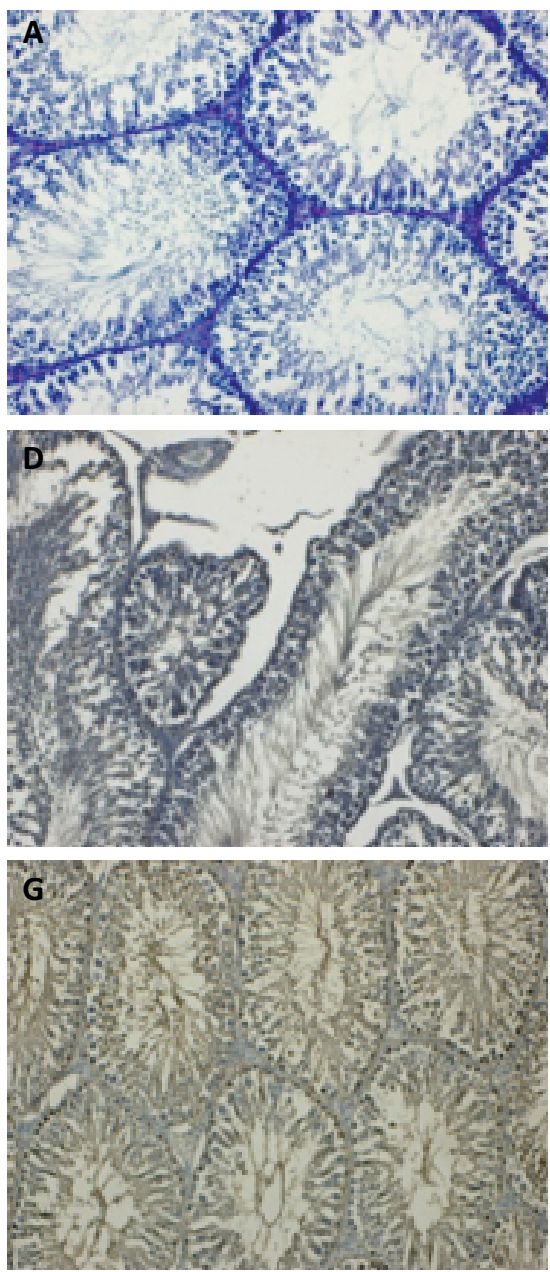
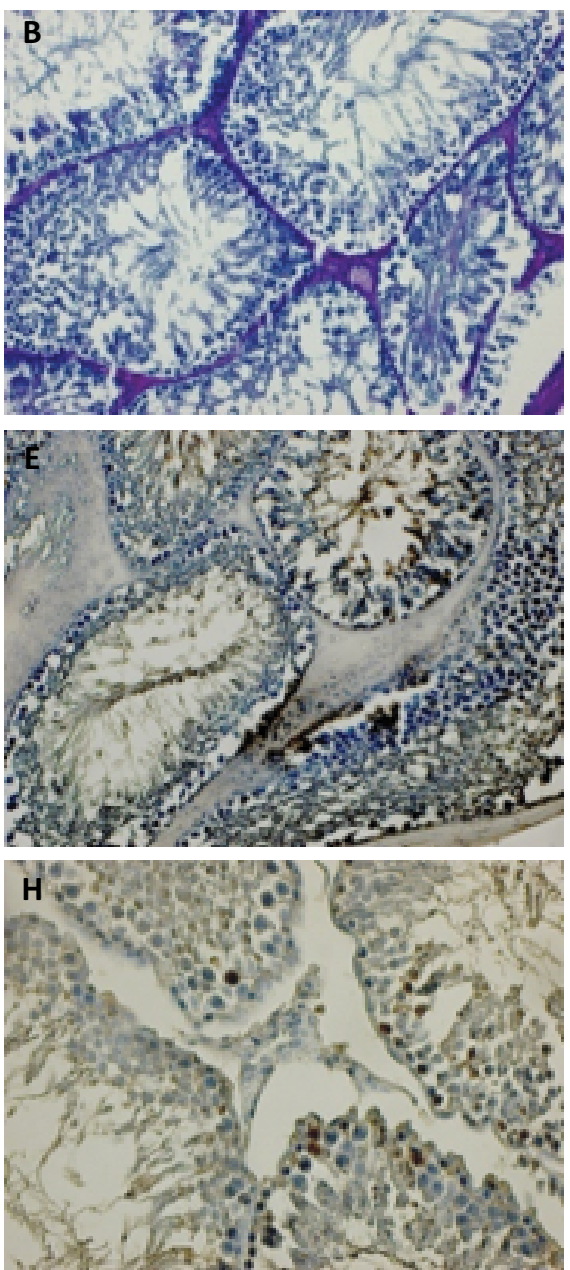
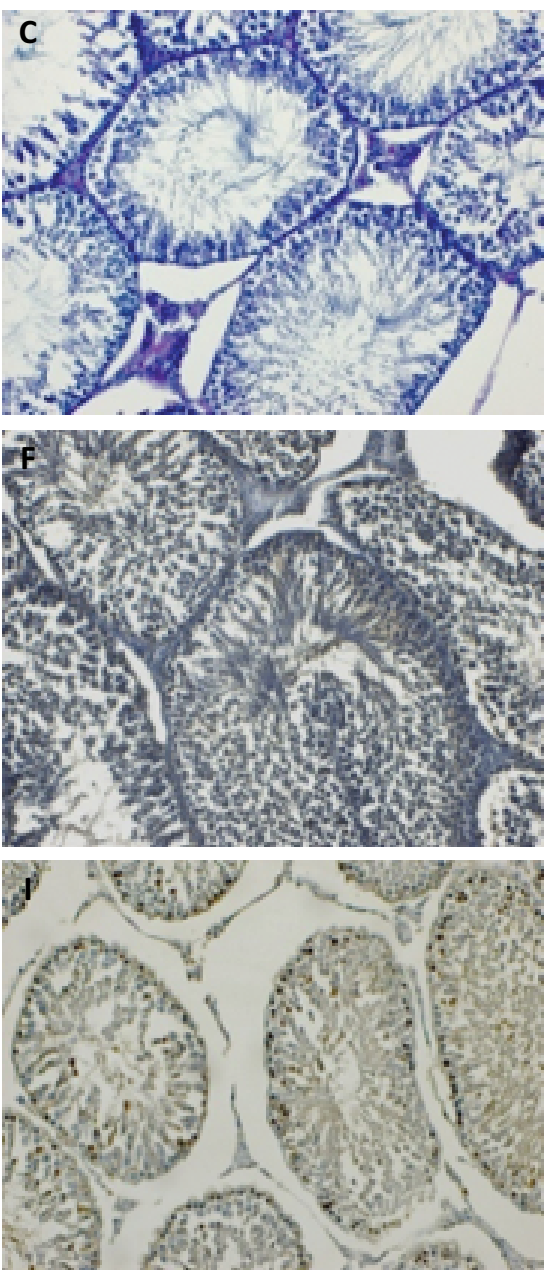

Figure 3 - A: Sham group: The spermatogenic cells of the seminiferous tubules in the control group with strong mitotic activity, Sertoli cells with regular broad luminal faces. Normal membrane thickness, interstitial area, blood vessels and Leydig cells, PAS staining Bar $50 \mu \mathrm{m}$. B: T/D group: An increased thickness of basal membrane in tubules, pyknosis and deterioration in the nucleus of spermatogenic cells, lack of maturation in sperm cells and degeneration of Sertoli cells, hemorrhage and dilatation of blood vessels, an increase in connective tissue, degeneration of Leydig cells, PAS staining Bar $50 \mu \mathrm{m}$. C: T/D+G. lucidum: Decreased basal membrane thickness of tubules, degeneration and deterioration of spermatic cells in some tubules and mitotic increase of spermatic cells in many tubules, small

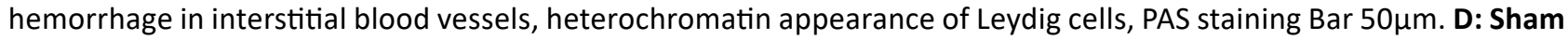
group: Negative VEGF expression in spermatogenetic and Sertoli cells in tubules, interstitial vascular endothelial cells and Leydig cells, VEGF staining Bar 50 $\mathrm{\mu m}$. E: T/D group: Positive expression of VEGF on apical surfaces of spermatogenic cells and Sertoli cells in tubules, VEGF expression positive in endothelial cells and some inflammatory cells in interstitial blood vessels and also in Leydig cells, VEGF staining Bar 50 $\mathrm{mm}$. F: T/D + G. lucidum group: positive VEGF expression in a few spermatogenic cells in some tubules, especially in vascular endothelial cells, Sertoli cells and negative VEGF expression in Leydig cells, VEGF staining Bar $50 \mu \mathrm{m}$. G: Sham group: Negative Bcl-2 expression in spermatogenic and Sertoli cells in the basal part of the tubules, positive Bcl-2 expression in some small spermatid cells near the lumen, Bcl-2 staining Bar $100 \mu \mathrm{m}$. H: T/D group: Dense Bcl-2 expression in spermatogenic cells showing potent mitotic activity in basal layers of tubules, Bcl-2 expression on the luminal faces of Sertoli cells, Bcl-2 staining Bar 50 $\mu \mathrm{m}$. I: T/D +G. lucidum group: Bcl-2 positive reaction in several spermatogenic cells in basal and apical regions of tubules, negative Bcl-2 reaction in Sertoli and Leydig cells, Bcl-2 staining Bar $50 \mu \mathrm{m}$. 


\section{- Discussion}

In our study, MDA levels were found to be significantly higher in the T/D group compared to the Sham and $T / D+G$. lucidum groups. The SOD, CAT and GSH levels were found to be significantly lower in the T/D group compared to the Sham and T/D+ G. lucidum groups. There was a decrease in the basal membrane thickness of tubules in the T/D+ G. lucidum group compared to the T/D group. While the T/D group was observed to have erupted spermatogenic cells with impaired nuclei, weakened maturation in the sperm cells and degenerated Sertoli cells, degenerated and impaired spermatic cells and mitotic increase were evident in some tubules of the $T / D+G$. lucidum group. Bleeding and dilatation of blood vessels in the interstitial region, increased connective tissue and impaired Leydig cells were evident in the T/D group, whereas a small amount of bleeding was observed in the blood vessels of the interstitial regular connective tissue cells and the heterochromatin Leydig cells in the $\mathrm{T} / \mathrm{D}+\mathrm{G}$. lucidum group.

In the present study, we did not study the effect of G. Iucidum on testicular I/R injury at different doses or different administration times. Detailed randomized controlled prospective clinical studies are required to assess the efficacy of $G$. lucidum on testis torsion.

Ozbek et al. ${ }^{14}$ suggested in an experimental study that testicular torsion significantly decreased SOD and CAT levels when compared to the control groups. In our study, the SOD and CAT activities in testicular tissue significantly increased in the $T / D+G$. lucidum group compared to the T/D group. Mestrovic et al. suggested that GSH activities in the ipsilateral testes of the treatment group were significantly higher than those in the T/D group ${ }^{15}$. In our study, GSH activities in testicular tissue significantly increased in the T/ $D+G$. lucidum group compared to the T/D group. Results from I/R studies of G. lucidum in brain, kidney and heart comply with the results of our study with decreased MDA and increased SOD and $\mathrm{GSH}^{16}$. In the literature, there are testis I/R studies using apocynin, nifedipine and urapidil. The results of these studies comply with ours with these medications reducing MDA levels and increasing SOD and GSH, showing antioxidant effect ${ }^{14,15,17}$. Histological alterations similar to the results in our study were also demonstrated in another testicular I/R study conducted by Ozbek et $a{ }^{14}$. Hirai et al. reported the protective effect of VEGF on histological damage in testicular torsion by preserving spermatogenic activity ${ }^{18}$. Tunçkıran et al. ${ }^{19}$ suggested that administering VEGF before reperfusion might have the potential to decrease long-term histologic damage after testicular torsion. In our study, VEGF expression was positive in the T/D group in the endothelial cells in the interstitial blood vessels, in some inflammatory cells and Leydig cells, in the apical faces of the spermatogenic cells and in Sertoli cells. In the T/D+ G. lucidum group, positive VEGF expression was observed in a small number of spermatogenic cells, especially in Sertoli cells, and it was negative in interstitial endothelial cells and Leydig cells. This may indicate that $G$. lucidum has a protective effect on VEGF expression linked to the testis. Kanter et al. ${ }^{12}$ stated that sensitivity to modulated apoptotic factors was higher in spermatogonia and spermatocytes, whereas Sertoli and Leydig cells were highly resistant. A study showed that the amount of VEGF and $\mathrm{Bcl}-2$ both decreased in testicular tissue, showing positive correlation in diabetic rats, and that both proteins were involved in cell proliferation, apoptosis and angiogenesis in the pathophysiology of diabetes ${ }^{13}$. In our study, intense $\mathrm{Bcl}-2$ expression was observed in spermatogenic cells with strong mitotic activity in the basal layers of tubules in the T/D group. Bcl2 expression was also found to be higher in Sertoli cells. Bcl-2-positive germinal cells were fewer in the G. lucidum-treated group compared to the T/D group. G.lucidum administered after T/D injury was estimated to decrease the effect of $\mathrm{Bcl}-2$ expression and inhibit apoptosis. A similar study by Sumii et al. ${ }^{20}$ showed that urocortin reduced $\mathrm{Bcl}-2$ expression and had an antiapoptotic effect.

\section{- Conclusions}

G. lucidum administration may decrease oxidative stress and histopathological damage. G. lucidum has a significant protective effect against testicular T/D damage in rats. This protective effect is thought to be mainly due to its antioxidative property, and it is thought to induce angiogenic effect and decrease apoptotic development. The use of G. lucidum therapy after reperfusion may be an alternative to germ cell degeneration resulting from testicular torsion and associated infertility.

\section{- Acknowledgements}

To Prof. Dr. Engin Deveci, Department of Histology and Embryology (Medical Faculty, Dicle University, Diyarbakir, Turkey) for his assistance with histopathologic and immunohistochemical evaluation, and Yasin Kenesarı, Department of Biochemistry (Mardin Kızıltepe Training and Research Hospital, Mardin, Turkey.) 


\section{- References}

1. Pogorelić Z, Mrklić I, Jurić I. Do not forget to include testicular torsion in differential diagnosis of lower acute abdominal pain in young males. J Pediatr Urol. 2013;9(6 Pt B):1161-5. doi: 10.1016/j.jpurol.2013.04.018.

2. Pogorelić Z, Mrklić I, Jurić I, Biočić M, Furlan D. Testicular torsion in the inguinal canal in children. J Pediatr Urol. 2013;9:793-7. doi: 10.1016/j.jpurol.2012.10.013.

3. Unsal A, Eroglu M, Avci A, Cimentepe E, Guven C, Derya Balbay $M$, Durak I. Protective role of natural antioxidant supplementation on testicular tissue after testicular torsion and detorsion. Scand J Urol Nephrol. 2006;40:1722. doi: $10.1080 / 00365590500407514$.

4. Cvetkovic T, Stankovic J, Najman S, Pavlovic D, Stokanovic D, Vlajkovic S, Dakovic-Bjelakovic M, Cukuranovic J, Zivkovic V, Stefanovic V. Oxidant and antioxidant status in experimental rat testis after testicular torsion/ detorsion. Int J Fertil Steril. 2015;9:121-8. doi: 10.22074/ ijfs.2015.4216.

5. Pogorelić Z, Mustapić K, Jukić M, Todorić J, Mrklić I, Meštrović J, Jurić I, Furlan D. Management of acute scrotum in children: a 25-year single center experience on 558 pediatric patients. Can J Urol. 2016;23(6):8594-601.

6. Sharp VJ, Kieran K, Arlen AM. Testicular torsion: diagnosis, evaluation, and management. Am Fam Physician. 2013;88(12):835-40.

7. Ji Z, Tang $Q$, Zhang J, Yang $Y$, Jia W, Pan $Y$. Immunomodulation of RAW264.7 macrophages by GLIS, a proteopolysaccharide from Ganoderma lucidum. J Ethnopharmacol. 2007;112:445-50. doi: 10.1016/j. jep.2007.03.035.

8. Wasser SP, Weis AL. Therapeutic effects of substances occurring in higher Basidiomycetes mushrooms: a modern perspective. Crit Rev Immunol. 1999;19:65-96.

9. Jones S, Janardhanan KK. Antioxidant and antitumor activity of Ganodermalucidum (Curt.: Fr.) P. Karst.Reishi (Aphyllophoromycetideae) from South India. Int J Med Mushr. 2000;2:195-200. doi: 10.1615/ IntJMedMushr.v2.i3.20.

10. Bozlu M, Acar D, Cayan S, Aktas S, Tunckiran A. Protective effect of trapidil on long-term histologic damage in a rat model of testicular ischemia-reperfusion injury. World J Urol. 2009;27:117-22. doi: 10.1007/s00345-008-0323-7.
11. Ellati RT, Parviz KK, Terry TT, Jeffrey J, Lysiak JJ. Twist and shout: a clinical and experimental review of testicular torsion. Korean J Urol. 2009;50:1159-67. doi: 10.4111/ kju.2009.50.12.1159.

12. Kanter M, Topcu Tarladacalisir Y, Parlar S. Antiapoptotic effect of L-carnitine on testicular irradiation in rats. J Mol Hist. 2010;41:121-8. doi: 10.1007/s10735-010-9267-5.

13. İrtegün S, Deveci E. Examining the expression level of VEGF and $\mathrm{Bcl}-2$ by immunohistochemistry and Western Blot in testis tissue of diabetic rats. Dicle Med J. 2016;43(4):52733. doi: 10.5798/diclemedj.0921.2016.04.0724.

14. Ozbek O, Altintas R, Polat A, Vardi N, Parlakpinar $H$, Sagir M, Duran Z.R, Yildiz A. The protective effect of apocynin on testicular ischemia-reperfusion injury. J Urol. 2015;193(4):1417-22. doi: 10.1016/j.juro.2014.11.086.

15. Meštrović J, Pogorelić Z, Drmić-Hofman I, Vilović K, Todorić D, Popović M Protective effect of urapidil on testicular torsion-detorsion injury in rats. Surg Today. 2017;47(3):393-8. doi: 10.1007/s00595-016-1388-3.

16. Zhong $D$, Wang $H$, Liu $M$, Li $X$, Huang $M$, Zhou $H$, Lin S, Lin Z, Yang B. Ganoderma lucidum polysaccharide peptide prevents renal ischemia reperfusion injury via counteracting oxidative stress. Sci Rep. 2015;25(5):16910. doi: 10.1038/srep16910.

17. Mestrovic J, Drmić-Hofman I, Pogorelić Z, Vilović K, Šupe-Domić D, Šešelja-Perišin A, Capkun V. Beneficial effect of nifedipine on testicular torsion-detorsion injury in rats. Urology. 2014;84(5):1194-8. doi: 10.1016/j. urology.2014.07.022.

18. Hirai S, Hatayama N, Naito M, Nagahori K, Kawata S, Hayashi S, Qu N, Terayama H, Shoji S, Itoh M.Pathological effect of arterial ischaemia and venous congestion on rat testes. Sci Rep. 2017;7(1):5422. doi: 10.1038/s41598017-05880-2.

19. Tunçkıran A, Cayan S, Bozlu M, Yilmaz N, Acar D, Akbay E. Protective effect of vascular endothelial growth factor on histologic changes in testicular ischemia-reperfusion injury. Fertil Steril. 2005;84:468-73. doi: 10.1016/j. fertnstert.2005.01.144.

20. Sumii K, Miyake H, Enatsu N, Chiba K, Fujisawa M .Characterization of urocortin as an anti-apoptotic protein in experimental ischemia-reperfusion model of the rat testis. Biochem Biophys Res Commun. 2016;479(2):38792. doi: 10.1016/j.bbrc.2016.09.091. 


\section{Correspondence:}

Gül Doğan

Hitit Üniversitesi Erol Olçok Eğitim ve Araştırma

Hastanesi Çocuk Cerrahisi Kliniği

Çepni Mahallesi, İnönü Cd. 176

Çorum Turkey

Postal Code: 19200

Phone: +90 5052711200

guldemirdag_982@hotmail.com

Received: Sept 22, 2019

Reviewed: Nov 24, 2019

Accepted: Dec 21, 2019
Conflict of interest: none

Financial source: none

This is an Open Access article distributed under the terms of the Creative Commons Attribution License, which permits unrestricted use, distribution, and reproduction in any medium, provided the original work is properly cited.

${ }^{1}$ Research performed at Hitit University Faculty of Medicine, Department of Pediatric Surgery, Çorum, Turkey. 